\title{
Small-Signal Modeling of Marine Electromagnetic Detection Transmitter Controlled-Source Circuit
}

\author{
Haijun Tao, ${ }^{1,2}$ Yiming Zhang, ${ }^{1}$ and Xiguo Ren ${ }^{1}$ \\ ${ }^{1}$ College of Electronic Information and Control Engineering, Beijing University of Technology, Beijing 100124, China \\ ${ }^{2}$ School of Electrical Engineering and Automation, Henan Polytechnic University, Jiaozuo, Henan 454003, China
}

Correspondence should be addressed to Haijun Tao; taohj99@hpu.edu.cn

Received 4 May 2015; Revised 24 August 2015; Accepted 24 August 2015

Academic Editor: Laurent Mevel

Copyright (c) 2015 Haijun Tao et al. This is an open access article distributed under the Creative Commons Attribution License, which permits unrestricted use, distribution, and reproduction in any medium, provided the original work is properly cited.

\begin{abstract}
Marine electromagnetic transmitter transmits electromagnetic waves with large power frequency conversion to the seabed to obtain the submarine structure and mineral resources. However, the current transmitter presents several problems, such as low efficiency, serious heat, and poor adaptability to the load. Soft-switching controlled-source circuit is used to reduce circuit losses. The mathematical model of controlled-source circuit should be established to realize a closed-loop control for increasing the output transient performance of electromagnetic waves. Given that the soft-switching controlled-source circuit has more status and that direct modeling is difficult, small-signal model of soft-switching controlled-source circuit is established based on that of hardswitching controlled-source circuit by analyzing the effect of output filter inductor current transformer leakage inductance and input voltage soft-switching controlled circuit on change in the duty cycle. Finally, experiments verify the accuracy and validity of the model.
\end{abstract}

\section{Introduction}

The exploration and exploitation of marine resources have high degrees of drilling and investment risks. To improve the success rate of drilling, the major oil companies in the world constantly conduct a variety of exploration activities (seismic, gravity, magnetic, etc.) prior to well drilling. Marine controlled-source electromagnetic detection has become an important approach for reducing the risk in deep-water drilling oil and gas resources by distinguishing between oil and water traps nature, which, in turn, exposes "the high impedance body" under the coverage [1]. Marine controlledsource electromagnetic detection system supplies the transmitter on the seabed by tugs. The multicomponent electromagnetic receiver laid on the seabed measures electromagnetic field values. Calculating the apparent resistivity and phase or directly using the electric and magnetic fields detects the distribution characteristics of underground electrical current. Such a method can reveal the distribution of the underlying structure, as well as oil, gas, and other mineral resources [2].
Marine electromagnetic survey techniques and instruments have been developed since the 1970s. The chief organizations in this field include the United States Scripps Institution of Oceanography, the German Leibniz Institute of Marine Sciences, the British Association of Subsea Equipment, and Japanese TIERRA companies [3]. Meanwhile, the major marine electromagnetic detection service companies in the world, such as the Norwegian company Electro Magnetic Geo Services, the British company Offshore Hydrocarbons Mapping, AGO company in the United States, and MTEM company in the UK, have conducted numerous marine electromagnetic detection projects [4].

Marine electromagnetic transmitter has a large size and weight, low efficiency, and poor transient waveform emissions; these properties hinder the fulfillment of the needs of the oil exploration industry practice [2]. Based on conventional hard-switching full-bridge DC/DC controlled-source circuit, a soft-switching controlled-source circuit is designed. The control circuit must be designed accordingly to obtain good dynamic and static output characteristics $[5,6]$. The design of the control loop is closely related to the main circuit 


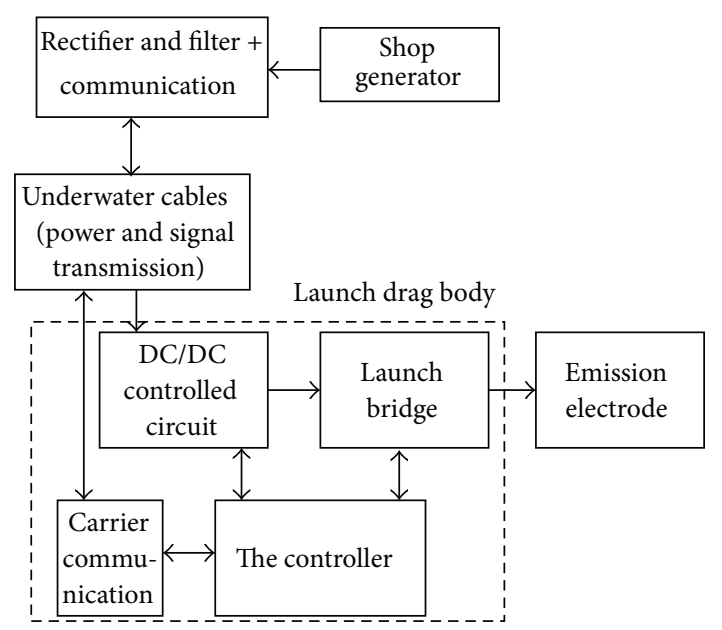

FIGURE 1: Diagram of marine electromagnetic transmitter.

structure and parameters [7]. Therefore, a mathematical model of controlled-source circuit must be established prior to designing the control system. However, the soft-switching controlled-source circuit has 12 types of working conditions in a duty cycle [8-10], thus causing difficulty in directly obtaining the transfer function.

In this paper, the ideal, state-space averaged, and smallsignal models of hard-switching controlled-source circuit are established. On this basis, a small-signal model of softswitching controlled-source circuit is established by analyzing the effect of the output filter inductor current transformer leakage inductance and input voltage source circuit on softswitching controllable duty cycle. Finally, the accuracy and validity of the model are verified through an experiment.

\section{Operation of Marine Electromagnetic Detection Transmitter}

The operation of a marine controlled-source electromagnetic detection system is depicted in Figure 1. The system chiefly includes shipboard diesel generators, deck-side rectifier filter circuits, deck-side PC monitor unit, underwater streamers, full-bridge DC/DC converter circuits, launch circuits, emitter electrode, control unit of the transmission system, and carrier communication.

The shipboard generator provides the initial energy for the entire controlled-source electromagnetic detection system. The deck-side rectifier filter circuits rectify the threephase $\mathrm{AC}$ voltage generated by the generator into a direct current, reducing the transmission loss through shipboard towing. After the electromagnetic detection transmitter gets the seabed, the deck-side PC monitor unit can establish remote communications between the underwater streamer and the control unit of the transmitter. Moreover, the deckside PC monitor unit has a time service function for the entire system. The ship underwater streamers connect the ship and the transmitter for power and signal transmission. Underwater DC/DC converter circuits transform the high-voltage direct current by the underwater streamers to

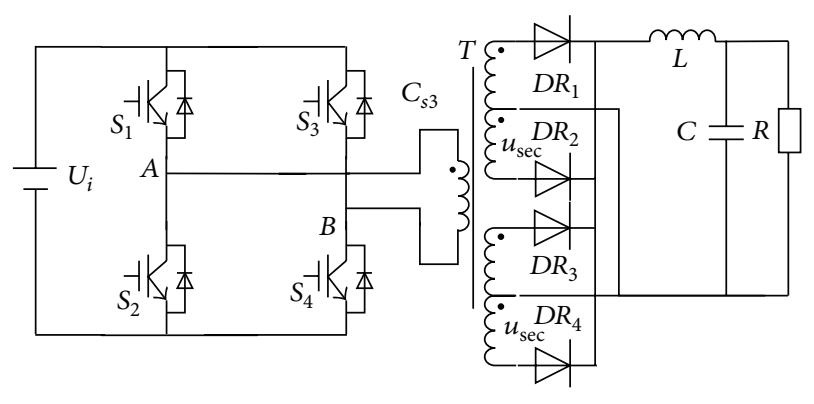

FIGURE 2: Controllable source circuit schematics.

a controllable DC current. The launch circuits subsequently reverse this controllable DC current into a frequency tunable square wave AC current. Ultimately, the final current would be transmitted by the emitter electrode to the seawater. The control unit of the transmission system with dual DSP could control the DC-DC converter circuits and the launch circuits and could detect the transmitter state. The underwater carrier communication (i.e., two-way fiber optic communication) establishes a communication connection with the transmitter and $\mathrm{PC}$ monitor unit.

The DC/DC controlled-source transmitter circuit is a key part of an ocean observation system, and its dynamic characteristics and efficiency directly affect the performance of the entire transmitter. Output voltage and current control accuracy and circuit efficiency could be improved using soft-switching controlled-source circuit. However, this circuit requires the use of a closed-loop control system. Therefore, a controlled-source circuit modeling is necessary. However, this circuit requires the use of a closed-loop control system. Thus, controlled-source circuit modeling is necessary, but the soft-switching controlled-source circuit has 12 states for one cycle, and direct modeling is difficult. The processes of hard-switching and soft-switching controlled-source circuits are initially analyzed to identify the differences and similarities between the two circuits. A soft-switching smallsignal model of marine transmitter controlled-source circuit is subsequently obtained based on the established hardswitching controlled source of small-signal circuit model.

\section{Operation Process Analysis of Controlled-Source Circuit}

3.1. Controlled-Source Circuit Structure. As shown in Figure 2, the controlled-source circuit structure includes an inverter bridge consisting of four IGBTs, a high-frequency transformer with a center tap, and a high-frequency rectifier filter. The major difference between hard-switching and softswitching controlled-source circuits is the value of the transformer leakage inductance $L_{r}$. The transformer leakage inductance $L_{r}$ in hard-switching controlled-source circuit is extremely small, which can be negligible, to reduce the value of impulse voltage of the primary side of the transformer at IGBT turning-off time. For soft-switching circuit, transformer leakage inductance is large to provide bridge arm capacitors with sufficient energy to achieve IGBT ZVS during 


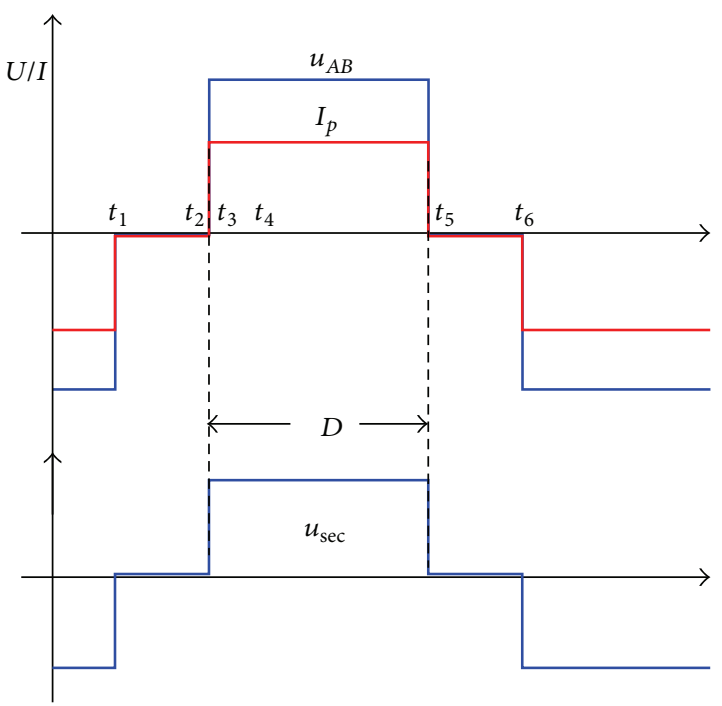

FIGURE 3: Main waveform of hard-switching controlled-source circuit.

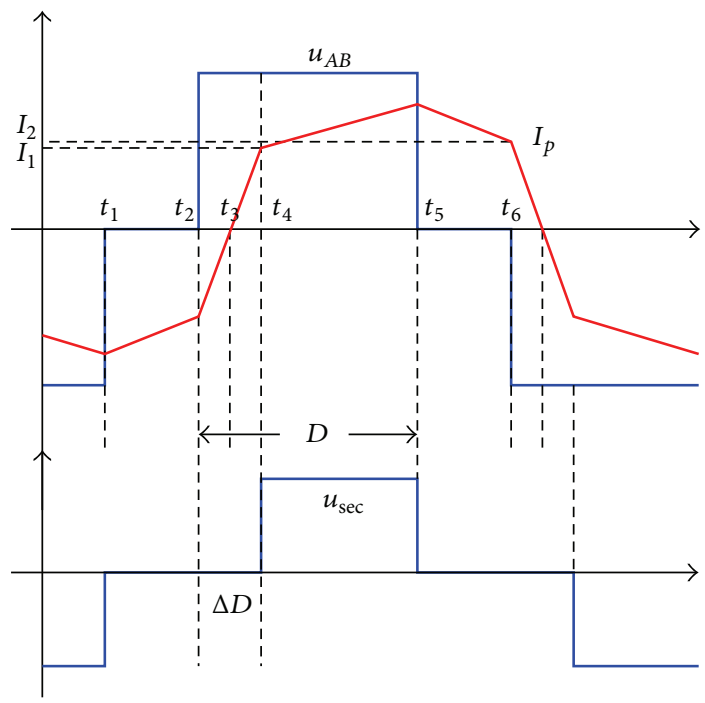

FIGURE 4: Main waveform of soft-switching controlled-source circuit.

the freewheeling period. In terms of control mode, hardswitching circuit uses bipolar control, whereas soft-switching circuit uses phase-shifted control.

3.2. Operation Process Analysis. Primary voltage and current and secondary voltage waveform of high-frequency transformer for hard-switching controlled-source circuit and softswitching controlled-source circuit are shown in Figures 3 and 4, respectively. These figures show that the voltage waveform type of these forms of circuit in a given duty ratio control is approximation, and the difference is the duty cycle loss because of leakage inductance in the soft-switching controlled-source circuit.

Two equivalent circuits shown in Figure 5 can be obtained through the analysis of controlled-source circuit from the output. These circuits correspond to operation states when power flows from the primary side of transformer transfer to secondary side and when the secondary side is freewheeling. Thus, a mathematical model of soft-switching controlled-source circuit can be derived by obtaining the mathematical model of hard-switching controlled-source circuit.

\section{Hard-Switching Controlled-Source Circuit Modeling}

4.1. Ideal Switch Model. According to the equivalent switching states illustrated in Figure 5 and Kirchhoff's voltage and current law, the equation of state of the circuit can be obtained

$$
\begin{array}{ll}
\dot{x}=A_{1} x+B_{1} u, & \\
y=C_{1} x, & t \in\left[t_{i}, t_{i}+D T_{s}\right], \\
\dot{x}=A_{2} x+B_{2} u, & \\
y=C_{2} x, & t \in\left[t_{i}+D T_{s}, t_{i+1}\right],
\end{array}
$$

where

$$
\begin{aligned}
& A_{1}=\left[\begin{array}{cc}
0 & -\frac{1}{L} \\
\frac{1}{C} & -\frac{1}{R C}
\end{array}\right] \text {, } \\
& B_{1}=\left[\begin{array}{c}
\frac{1}{n L} \\
0
\end{array}\right] \text {, } \\
& C_{1}=\left[\begin{array}{ll}
\frac{1}{n} & 0 \\
0 & 1
\end{array}\right] \text {, } \\
& A_{2}=\left[\begin{array}{rr}
0 & -\frac{1}{L} \\
\frac{1}{C} & -\frac{1}{R C}
\end{array}\right] \text {, } \\
& B_{2}=\left[\begin{array}{l}
0 \\
0
\end{array}\right] \text {, } \\
& C_{2}=\left[\begin{array}{ll}
0 & 0 \\
0 & 1
\end{array}\right] \text {, } \\
& x=\left[\begin{array}{l}
i_{L} \\
u_{C}
\end{array}\right] \text {, } \\
& y=\left[\begin{array}{l}
i_{i} \\
u_{o}
\end{array}\right], \\
& u=\left[u_{i}\right] \text {. }
\end{aligned}
$$




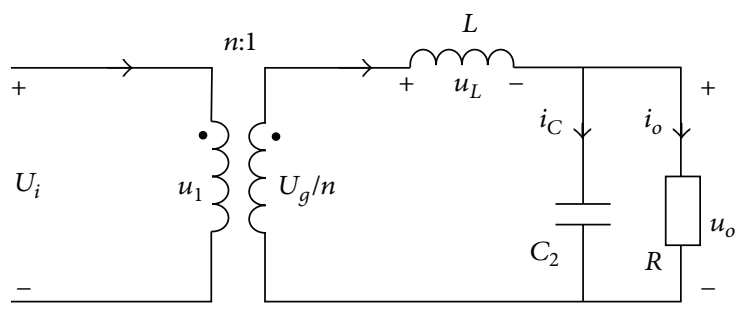

(a)

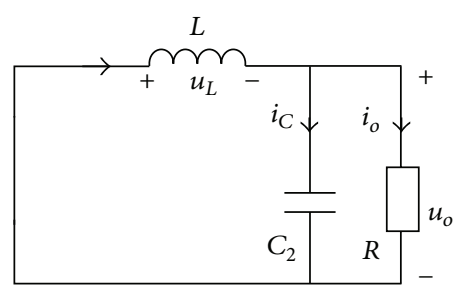

(b)

FIGURE 5: Equivalent switching state.

Ideal switch model is very close to the characteristics of the actual circuit. The results using this model for analysis are in accordance with the actual situation. However, ideal switch model is a typical time-varying system. If the duty cycle is as an input variable, then the product item of the input variable and the input variable $u$ exist. Thus, the system is nonlinear. Obtaining an analytical solution is difficult for nonlinear time-varying systems. Hence, an ideal switch model needs to eliminate the time-varying characteristics to obtain analytical solutions.

4.2. State-Space Averaged Model. Ideal switch model is timevarying, but its topology and state equation are determined to be time-invariant when the switches are conducting and is turned off. According to the circuit schematic and (1), $A_{1}$, $B_{1}$, and $C_{1}$ apply for the first (on) interval, or during $D$ of the switching time, while $A_{2}, B_{2}$, and $C_{2}$ exist during the $1-D$ (off) switching time interval. The system average approximate state equation in a switching cycle can then be obtained

$$
\begin{aligned}
& \dot{x}=A x+B u, \\
& y=C x,
\end{aligned}
$$

where $A=D A_{1}+(1-D) A_{2}, B=D B_{1}+(1-D) B_{2}, C=$ $D C_{1}+(1-D) C_{2}$.

The model described by (3) is the system state-space average model. The average state-space model is time-invariant and can simplify the task of obtaining the analytical solution. This model is important and effective for control system analysis and design of the controlled-source circuit. The following aspects must be considered:

(1) Compared with solutions derived from ideal switch model, the solutions derived from state-space average model allow greater approximation. In addition, fluctuations produced by state variables, such as the inductor current, and capacitance voltage with the switch turning-on and turning-off did not reflect in the solutions of state-space average model.

(2) State-space average model is only applicable to lower switch frequency range of 1/5-1/20 of the switching frequency, and the result would be meaningless if the frequency involved in the analysis process is close to or greater than the switching frequency.
4.3. Small-Signal Model. The control circuit controls controlled-source circuit by adjusting the duty cycle $D$. In this case, the duty cycle $D$ is an input variable quantity of controlled-source circuit but changes over time. Traditionally, $d$ is used and $D$ represents a fixed duty cycle. In the case that a duty cycle is used as an input quantity, the state-space average model is no longer linear. This phenomenon is due to the presence of coupling between the state variables and the control quantity, such as in (3), where the control amount $d$ and the system input amount $u$ multiply. Solving a local linear system, which has been a small-signal model, is usually necessary for conducting system analysis and design.

In state-space averaged model, the state equation of controlled-source circuit can be represented as a unified form as follows [11, 12]:

$$
\dot{x}=F(x, u, d) \text {. }
$$

Assuming that the static operating point of the circuit is $\left(x_{0}, u_{0}, d_{0}\right)$, the right side of (4) is expanded as a Taylor series in the vicinity of operation point, order $\widehat{x}=x-x_{0}, \widehat{u}=u-u_{0}$, $\widehat{d}=d-d_{0}$, and higher-order infinite events are ignored

$$
\begin{aligned}
\dot{\hat{x}}= & \frac{\partial F\left(x_{0}, u_{0}, d_{0}\right)}{\partial x} \widehat{x}+\frac{\partial F\left(x_{0}, u_{0}, d_{0}\right)}{\partial u} \widehat{u} \\
& +\frac{\partial F\left(x_{0}, u_{0}, d_{0}\right)}{\partial d} \widehat{d} .
\end{aligned}
$$

In the above equation, to allow $A=\partial F\left(x_{0}, u_{0}, d_{0}\right) / \partial x$, $B=\partial F\left(x_{0}, u_{0}, d_{0}\right) / \partial u$, and $C^{\prime}=\partial F\left(x_{0}, u_{0}, d_{0}\right) / \partial d$, smallsignal model state equation can be obtained as follows:

$$
\dot{\hat{x}}=A \widehat{x}+B \widehat{u}+C^{\prime} \widehat{d} .
$$

Coefficient matrices $A$ and $B$ are the same as those in (3). The static operating point of state variables and output variables of controlled-source circuit can be obtained by (3) $[13,14]$

$$
\begin{aligned}
& X=-A^{-1} B U, \\
& Y=\left(E-C A^{-1} B\right) U .
\end{aligned}
$$

Then,

$$
C^{\prime}=\left[\left(A_{1}-A_{2}\right) X+\left(B_{1}-B_{2}\right) U\right] .
$$




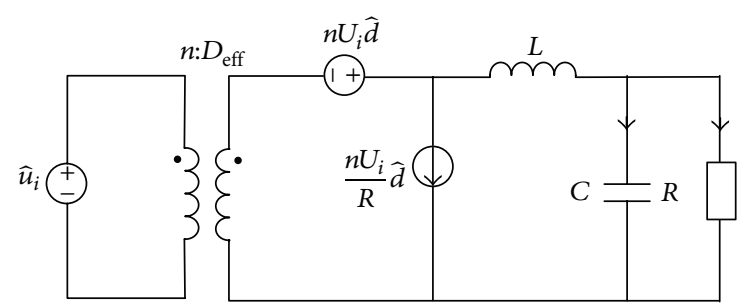

FIGURE 6: Small-signal model of hard-switching full-bridge circuit.

Using Laplace transform on small-signal model state equation (6), we can obtain small model state equation in complex frequency domain

$$
\begin{aligned}
s \widehat{x}(s)= & A \widehat{x}(s)+B \widehat{u}(s) \\
& +\left[\left(A_{1}-A_{2}\right) X+\left(B_{1}-B_{2}\right) U\right] \widehat{d}(s) .
\end{aligned}
$$

Transforming (9), we can derive the solution for smallsignal model state equation in the frequency domain:

$$
\begin{aligned}
\widehat{x}(s) & \\
= & (s I-A)^{-1} B \widehat{u}(s) \\
& +(s I-A)^{-1}\left[\left(A_{1}-A_{2}\right) X+\left(B_{1}-B_{2}\right) U\right] \widehat{d}(s) .
\end{aligned}
$$

Small-signal model of hard-switching controlled-source circuit is illustrated in Figure 6.

Based on the small-signal model diagram of hard-switching controlled-source circuit shown in Figure 6, we can obtain control-output transfer function

$$
\frac{\widehat{u}_{o}(s)}{\widehat{d}(s)}=\frac{U_{i}}{n *\left(L C s^{2}+s L / R+1\right)} .
$$

\section{Soft-Switching Controlled-Source Circuit Modeling}

From the previous process analysis of hard-switching and soft-switching controlled-source circuits, the major difference between soft-switching and hard-switching circuits is the change of duty cycle, including static duty cycle loss and small-signal duty cycle adjustment.

5.1. Static Duty Cycle Loss. Controlled-source circuit must increase transformer leakage inductance to increase the load range of the zero-voltage switches. However, large leakage inductance induces the decline of primary current rise rate when voltage is applied to the primary side of the transformer. Current ramp reduces the effective duty $D_{\text {eff }}$ of transformer secondary voltage and seriously affects the dynamic performance of the converter.

The duty cycle of the primary side of the transformer can be obtained according to Figure 4

$$
D=\frac{t_{5}-t_{2}}{T_{s} / 2}
$$

Secondary duty (effective duty) can be derived as follows:

$$
D_{\text {eff }}=\frac{t_{5}-t_{4}}{T_{s} / 2}
$$

In the presence of the transformer leakage inductance, effective duty is smaller than the primary duty. The duty cycle loss is given by

$$
\Delta D=D-D_{\text {eff }}
$$

where $D$ is the duty cycle of the primary voltage determined by the control circuit and $\Delta D$ represents the duty cycle loss.

The primary current at time instant $t=t_{4}$ can be derived as

$$
I_{1}=n\left(I_{L}-\frac{\Delta I}{2}\right)
$$

where at time instant $t=t_{6}$

$$
I_{2}=n\left(I_{L}+\frac{\Delta I}{2}-(1-D) \frac{V_{o} T_{s}}{2 L}\right) .
$$

Based on Figure $4, \Delta D$ can be derived as

$$
\Delta D=\frac{I_{1}+I_{2}}{\left(U_{i} / L_{r}\right)\left(T_{s} / 2\right)} .
$$

By combining (15) and (16) into (17), we obtain

$$
\Delta D=\frac{1}{\left(U_{i} / L_{r}\right)\left(T_{s} / 2\right)}\left[2 I_{L}-\frac{u_{o}}{L}(1-D) \frac{T_{s}}{2}\right] .
$$

Considering (14), $D_{\text {eff }}$ can be obtained as follows:

$$
D_{\text {eff }}=D-\frac{1}{\left(U_{i} / L_{r}\right)\left(T_{s} / 2\right)}\left[2 I_{L}-\frac{u_{o}}{L}(1-D) \frac{T_{s}}{2}\right] .
$$

\subsection{Small-Signal Duty Cycle Adjustment}

(1) Duty Cycle Adjustment Caused by the Change of Output Filter Inductor Current. When steady-state operation of controlled-source circuit is perturbed by an increase of the filter inductor current, assuming the filter inductor current is denoted by $\hat{i}_{L}$, the primary current will reach the reflected filter inductor current at later time than it would in the steadystate operation. This phenomenon will cause a reduction of the duty cycle, which can be derived as follows:

$$
\widehat{d}_{i}=-\frac{\Delta t}{T_{s} / 2}=-\frac{4 n L_{r} f_{s}}{U_{i}} \hat{i}_{L} .
$$

(2) Duty Cycle Adjustment Caused by the Change of Input Voltage. When steady-state operation of controlled-source circuit is perturbed by an increase of the input voltage by the amount $\widehat{u}_{i}$, the slope of the primary current will increase to reach the reflected filter inductor current sooner than it would in the unperturbed operation. This phenomenon will cause an increase of the duty cycle, which can be obtained as follows:

$$
\widehat{d}_{u}=\frac{4 n f_{s} L_{r} I_{L}}{U_{i}^{2}} \widehat{u}_{i} .
$$




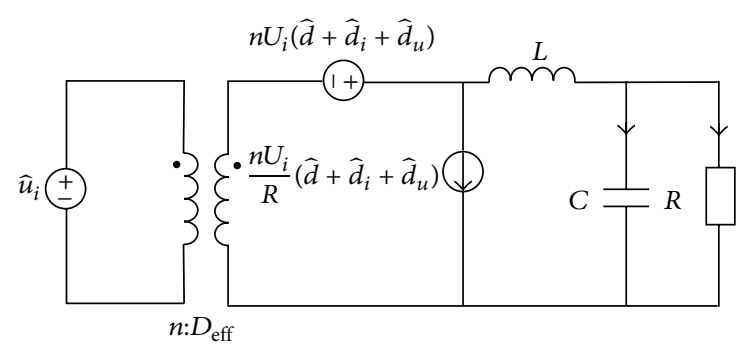

FIGURE 7: Small-signal circuit model of soft-switching controlledsource circuit.

5.3. Small-Signal Model. The above analysis is introduced into small-signal circuit model of hard-switching full-bridge circuit. In particular, $\widehat{d}_{\text {eff }}$ is used instead of $\widehat{d}$. Equivalent small-signal circuit model of soft-switching phase-shifted full-bridge converter can then be derived

$$
\widehat{d}_{\mathrm{eff}}=\widehat{d}+\widehat{d}_{i}+\widehat{d}_{u} \text {. }
$$

Small-signal circuit model of soft-switching controlledsource is illustrated in Figure 7.

Based on the small-signal model of soft-switching controlled-source circuit illustrated in Figure 7, the controloutput transfer function of the control system can be obtained

$$
\frac{\widehat{u}_{o}(s)}{\widehat{d}_{\text {eff }}(s)}=\frac{U_{i}}{n *\left(L C s^{2}+s\left(L / R+R_{d} C\right)+R_{d} / R+1\right)},
$$

where $R_{d}=4 n^{2} L_{r} f_{s}$. When $L_{r}=0$, the model of softswitching controlled-source circuit is evolved into the model of hard-switching controlled-source circuit.

As shown in (23), the function of internal current feedback reduces the low frequency gain of the transfer function, which is due to $R_{d} / R$. If $R_{d} / R$ is controlled within reasonable limits, which can be negligible, then

$$
\frac{\widehat{u}_{o}(s)}{\widehat{d}_{\mathrm{eff}}(s)}=\frac{U_{i} \omega_{0}^{2} / n}{s^{2}+2 \omega_{0} \xi s+\omega_{0}^{2}},
$$

where $\omega_{0}^{2}=1 / L C, \xi=(1 / 2 R) \sqrt{L / C}+\left(R_{d} / 2\right) \sqrt{C / L}$. The first item of $\xi$ is damping item caused by hard-switching controlled-source circuit. The second item is damping item caused by soft-switching controlled-source circuit due to the presence of the leakage inductance of the transformer.

\section{Simulation and Experiment}

Based on the preceding analysis, the small-signal model is verified by simulation and experiment for a $6 \mathrm{~kW}$ marine transmitter circuit shown in Figure 8. The circuit parameters are as follows: input voltage $U_{i}=540 \mathrm{~V}$, switching frequency $f_{s}=20 \mathrm{kHz}$, output voltage $U_{o}=34 \mathrm{~V}$, output filter inductor $L=20 \mu \mathrm{H}$, output filter capacitor $C=1000 \mu \mathrm{F}$, transformer leakage inductance $L_{r}=56 \mu \mathrm{H}$, and load $R=0.17 \Omega$.

(1) Simulation Analysis. The amplitude-frequency and phasefrequency characteristics of marine transmitter hard-switching controlled-source circuit are depicted by green lines and

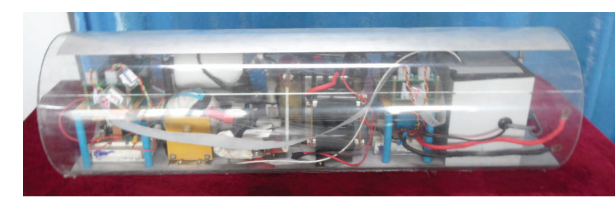

FIGURE 8: Physical picture of marine electromagnetic transmitter circuit.

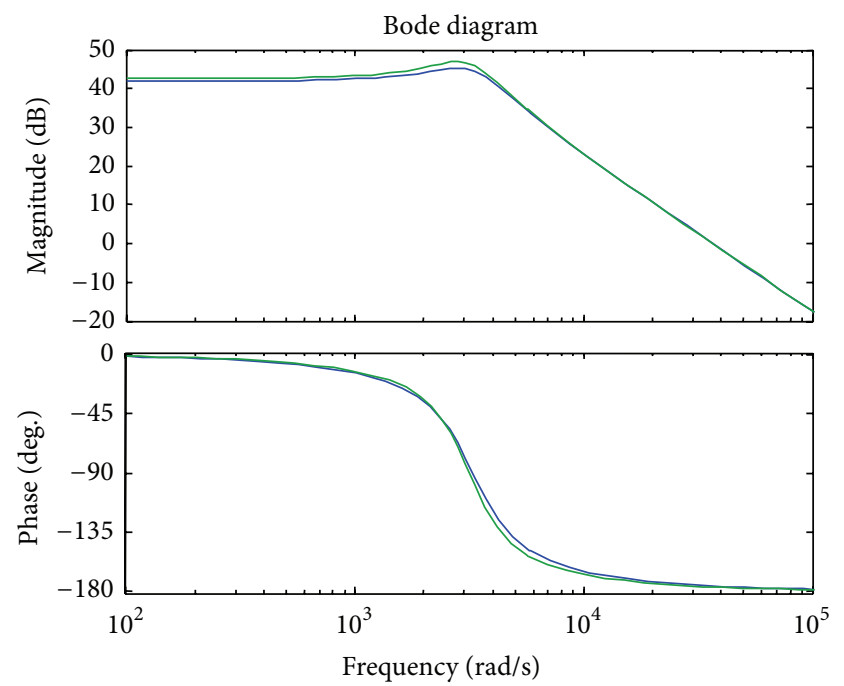

FIGURE 9: Control-to-output voltage transfer functions of hardswitching (green lines) and soft-switching (blue lines) controlledsource circuits.

those of marine transmitter soft-switching controlled-source circuit are depicted by blue lines, as illustrated in Figure 9 . This figure shows that the resonance peaks of DC gain between the two circuits are different. An inhibition term is added in the soft-switching circuit because of the function of the leakage inductance, which significantly reduced the resonance peak.

(2) Experiment Verification. The contrast curves of measured and predicted amplitude-frequency characteristics of the control-to-output transfer function are illustrated in Figure 10. This figure shows that the measured curve and prediction curve can be well fitted at low frequency, whereas large error is found in the high frequency because of the effect of high-frequency zero. The error of model prediction at high-frequency range has little effect on the control of the system. Hence, the model accurately reflects the actual circuit.

Transformer primary voltage and current waveforms of soft-switching controlled-source circuit and hard-switching controlled-source circuit are illustrated in Figures 11 and 12 , respectively. These figures show that the experimental results are consistent with the theoretical analysis. The voltage waveform is different from the current waveform as a result of phase shifting control mode.

The high-frequency voltage transformer primary and secondary voltage waveforms of soft-switching and hardswitching controlled-source circuits are illustrated in Figures 13 and 14, respectively. These figures show that the experimental results are consistent with the theoretical analysis. 


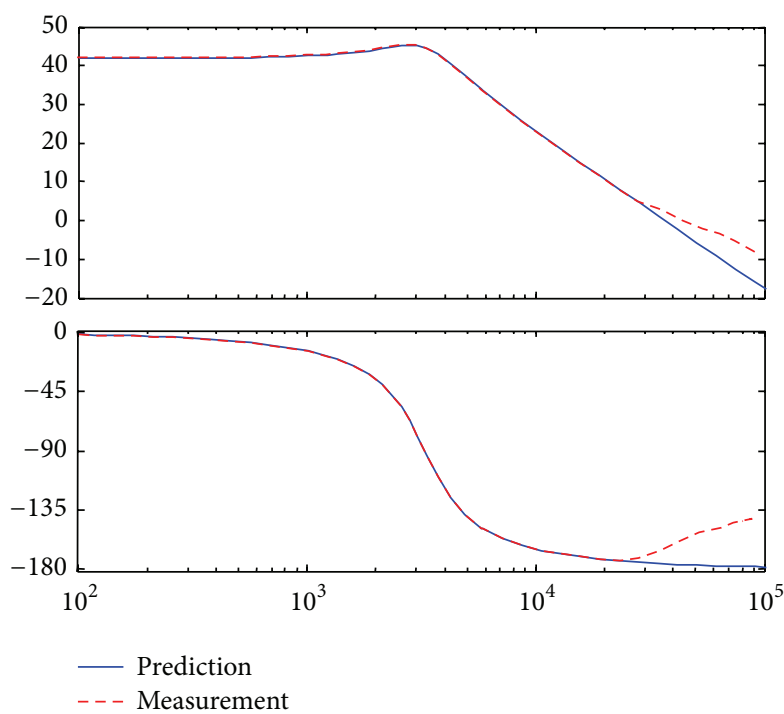

FIgURE 10: Control-to-output voltage transfer function of the controlled-source circuit. Model prediction (solid lines) and experimental measurement (dashed lines).

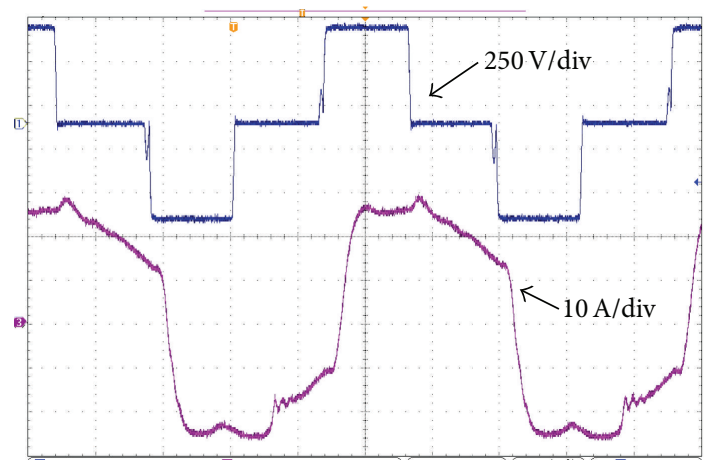

FIGURE 11: Primary voltage and current waveforms in soft-switching mode.

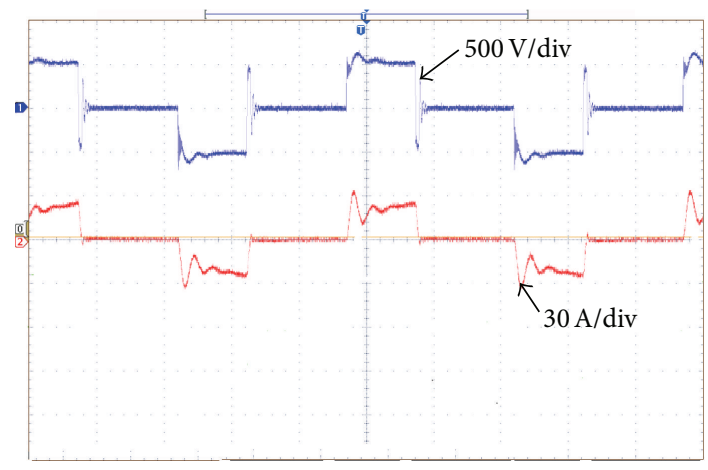

FIGURE 12: Primary voltage and current waveforms in hard-switching mode.

The duty cycle is less than the effective control duty cycle because of the presence of the leakage inductance of the transformer.

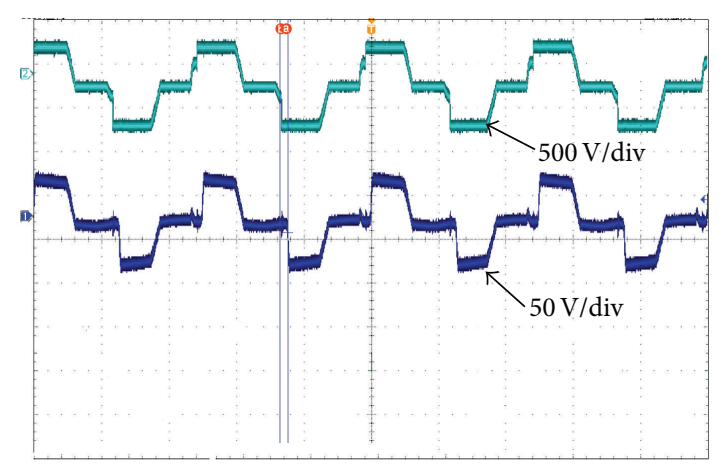

FIGURE 13: Primary and secondary voltage waveforms of transformer in soft-switching mode.

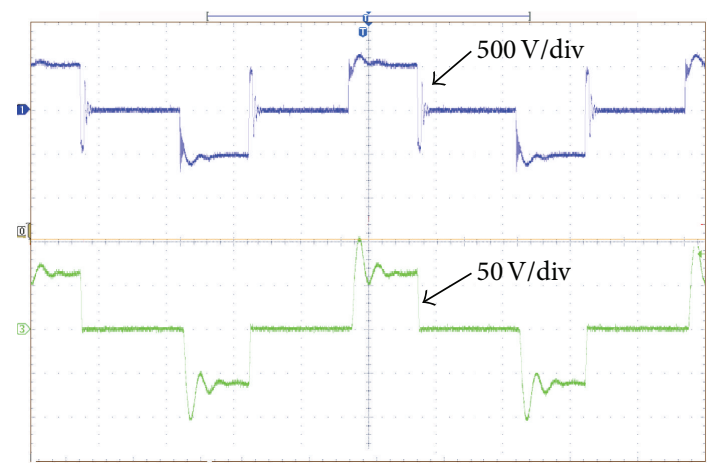

Figure 14: Primary and secondary voltage waveforms of transformer in hard-switching mode.

Output voltage and current waveforms of transmitter transmitting electrode in soft-switching and hard-switching modes are depicted in Figures 15 and 16, respectively. The emission frequency is $50 \mathrm{~Hz}$, the transmitting voltage is $34 \mathrm{~V}$, and the emission current is $200 \mathrm{~A}$. The output of electromagnetic transients is significantly improved by using controller designed with the proposed mathematical models.

The measure efficiency curves of marine electromagnetic detection transmitter using soft-switching controlled-source circuit and using hard-switching controlled-source circuit are illustrated in Figure 17. The maximum efficiency of the transmitter circuit using soft-switching controlled-source circuit is at $90 \%$ (including self-excitation auxiliary power supply), and the maximum efficiency of the transmitter circuit using hard-switching controlled-source circuit is at $83 \%$.

\section{Conclusions}

(1) Based on the analysis of the operation process of marine transmitter hard-switching and soft-switching controlled-source circuits, similarities and differences between the two circuits have been identified, and two equivalent circuits of controlled-source operation are obtained. On this basis, a mathematical model of controlled-source circuit can be established. 


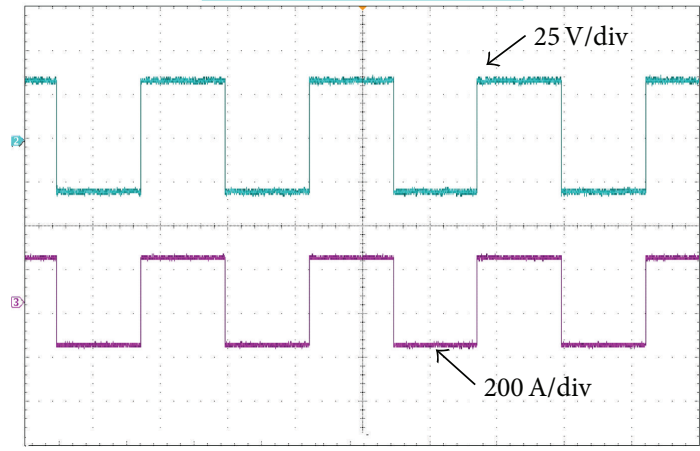

FIGURE 15: Output voltage and current waveforms of transmitter transmitting electrode in soft-switching mode.

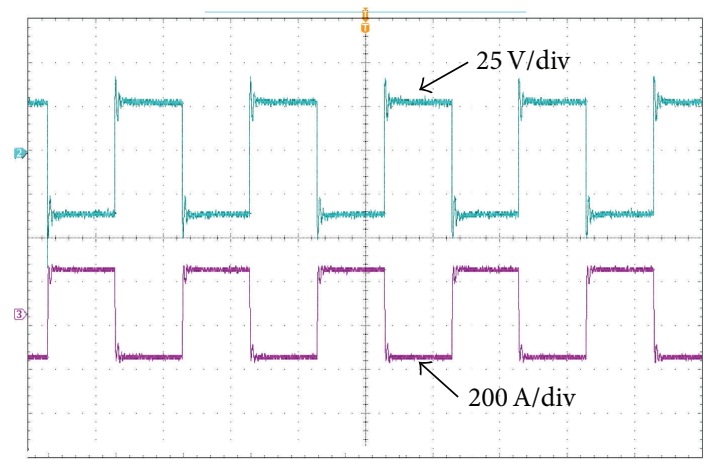

FIGURE 16: Output voltage and current waveforms of transmitter transmitting electrode in hard-switching mode.

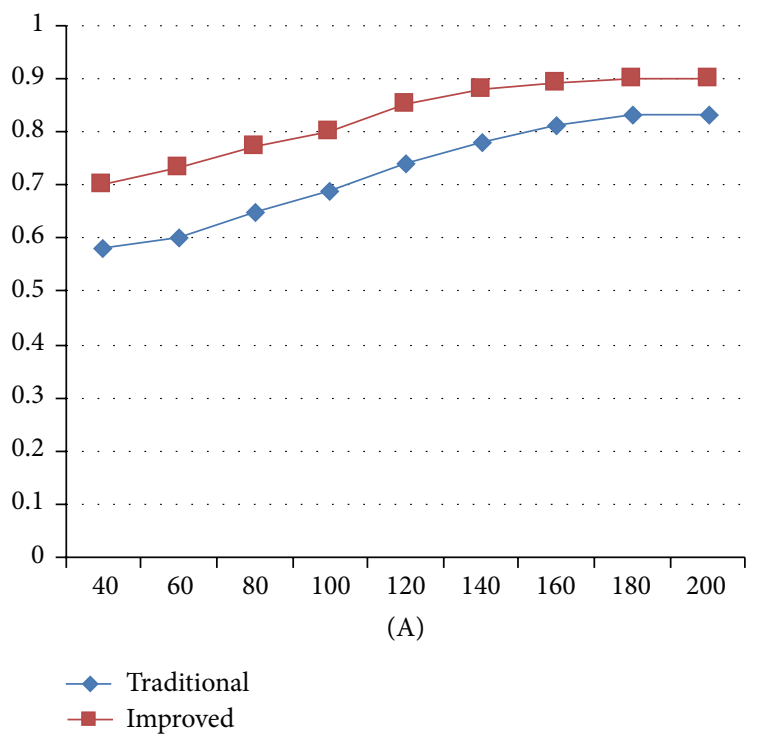

FIGURE 17: Measure efficiency of the proposed transmitter and conventional transmitter.

(2) Ideal switch model, state-space average model, and small-signal model are established based on the idealization method and abstract extent of hard-switching controlled-source circuit.
(3) Small-signal model and transmission function of softswitching controlled circuit are obtained based on the mathematical modeling of hard-switching controlled-source circuit by analyzing the effect of output filter inductor current transformer leakage inductance and input voltage soft-switching controlled source on change in the duty cycle.

(4) The proposed small-signal model is verified by simulation and experiment. The results are consistent with theoretical analysis. The controller designed with the proposed model has significantly improved the control accuracy and transient performance of the output electromagnetic wave of marine electromagnetic transmitter.

\section{Conflict of Interests}

The authors confirm that this paper content has no conflict of interests.

\section{Acknowledgments}

Authors wish to acknowledge assistance or encouragement from colleagues and financial support by R\&D of Key Instruments and Technologies for Deep Resources Prospecting (the National R\&D Projects for Key Scientific Instruments), Grant no. ZDYZ2012-1-05-01.

\section{References}

[1] S. C. Constable, A. S. Orange, G. M. Hoversten, and H. F. Morrison, "Marine magnetotellurics for petroleum exploration part I: a sea-floor equipment system," Geophysics, vol. 63, no. 3, pp. 816-825, 1998.

[2] S. Constable and L. J. Srnka, "An introduction to marine controlled-source electromagnetic methods for hydrocarbon exploration," Geophysics, vol. 72, no. 2, pp. WA3-WA12, 2007.

[3] M. Kurang, N. Misac, and L. Yaoguo, "Controlled source electromagnetic (CSEM) technique for detection and delineation of hydrocarbon reservoirs: an evaluation," in Proceedings of the 75th Annual Internat SEG Meeting: Expanded Abstracts, pp. 546-549, 2005.

[4] T. Eidesmo, S. Ellingsrud, L. M. Macgregor et al., "Re-mote detection of hydrocarbon filled layers using marinecontrolled source electromagnetic sounding," in Proceedings of the EAGE 64thConference \& Exhibition, pp. 27-30, Florence, Italy, May 2002.

[5] R. Erichson and D. Maksimovic, Fundamentals of Power Electronics, Kluwer Academic Publishers, New York, NY, USA, 2001.

[6] R. Kollman and J. Betten, "Closing the loop with a popular shunt regulator," Power Electronics Technology, vol. 46, no. 2, pp. 3036, 2003.

[7] R. D. Middlebrook and S. Cuk, "A general unified approach to modelling switching-converter power stages," International Journal of Electronics, vol. 42, no. 6, pp. 521-550, 1977.

[8] R. B. Ridley, "A new, continuous-time model for current-mode control," IEEE Transactions on Power Electronics, vol. 6, no. 2, pp. 271-280, 1991.

[9] V. Vorperian, "Simplified analysis of PWM converters using the model of the PWM switch: parts I and II," IEEE Transactions on 
Aerospace and Electronic Systems, vol. 52, no. 26, pp. 490-505, 1990.

[10] S. V. Mollov, M. Theodoridis, and A. J. Forsyth, "High frequency voltage-fed inverter with phase-shift control for induction heating," IEE Proceedings: Electric Power Applications, vol. 151, no. 1, pp. 12-18, 2004.

[11] N. S. Bayindir, O. Kukrer, and M. Yakup, "DSP-based PLLcontrolled $50 \sim 100 \mathrm{kHz} 20 \mathrm{~kW}$ high-frequency induction heating system for surface hardening and welding applications," IEE Proceedings-Electric Power Applications, vol. 150, no. 3, pp. 365-371, 2003.

[12] C. P. Basso, Switch-Mode Power Supplies, Spice Simulations and Practical Designs, The McGraw-Hill Companies, Paris, France, 2008.

[13] C. P. Basso, Designing Control loops for Linear and Switching Power Supplies, Artech House, Paris, France, 2012.

[14] L. Dixon, "Average current mode control of switching power supplies," in Product \& Application Handbook, Unitrode, pp. 356-369, 1993-1994. 


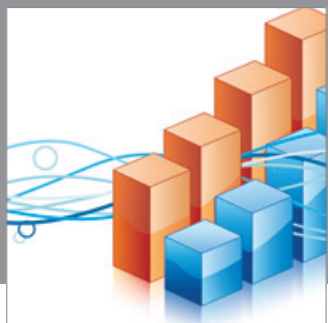

Advances in

Operations Research

mansans

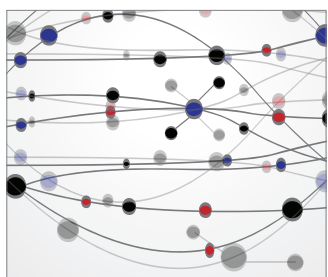

The Scientific World Journal
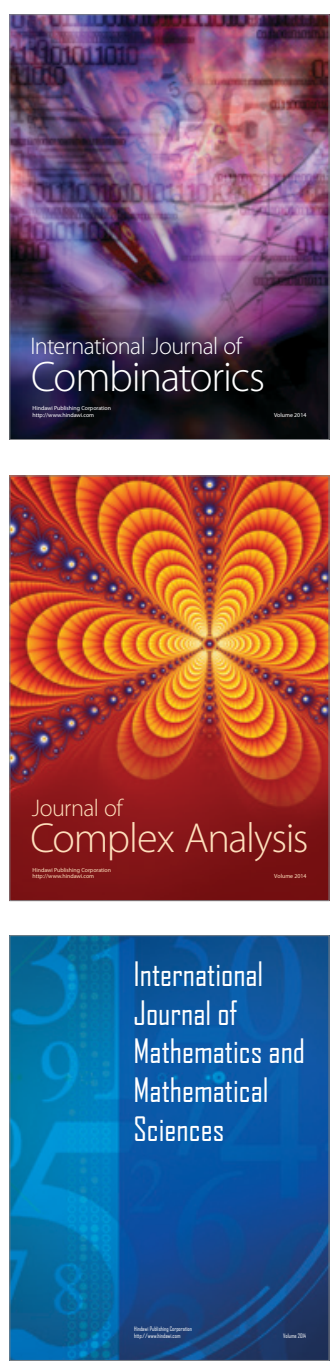
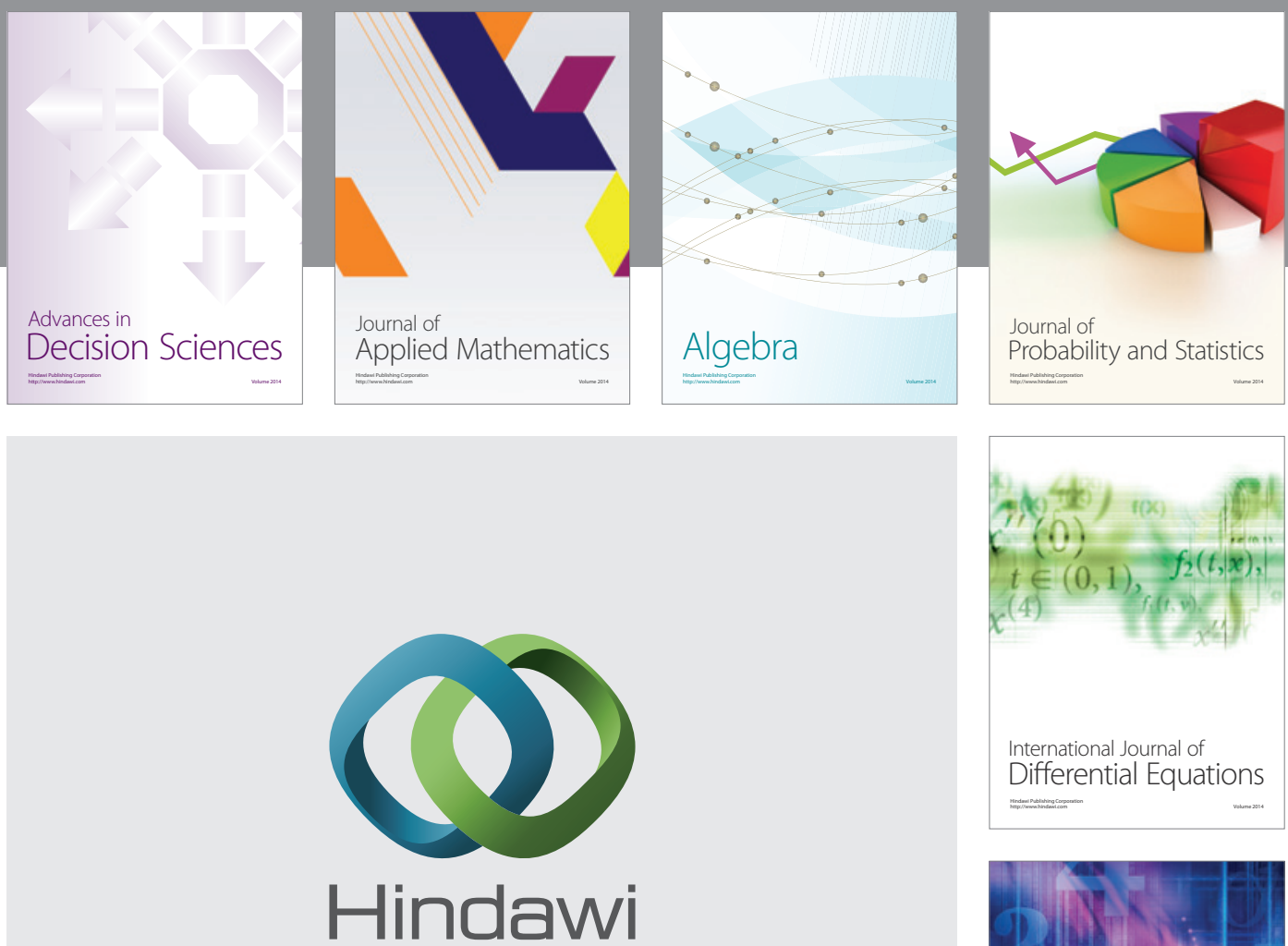

Submit your manuscripts at http://www.hindawi.com
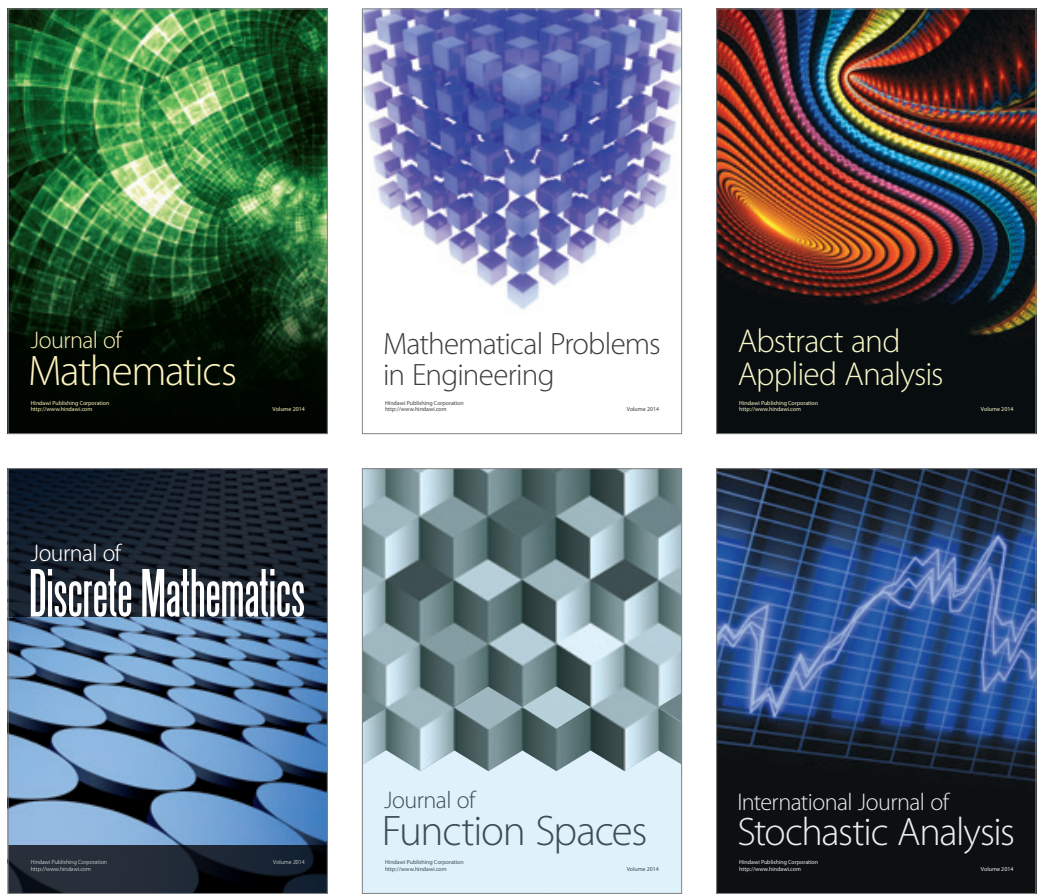

Journal of

Function Spaces

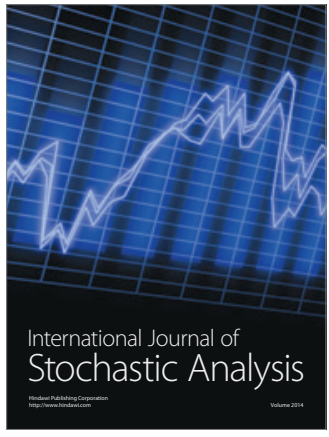

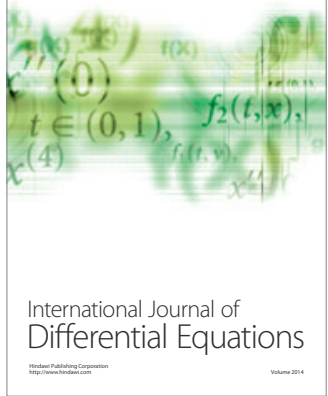
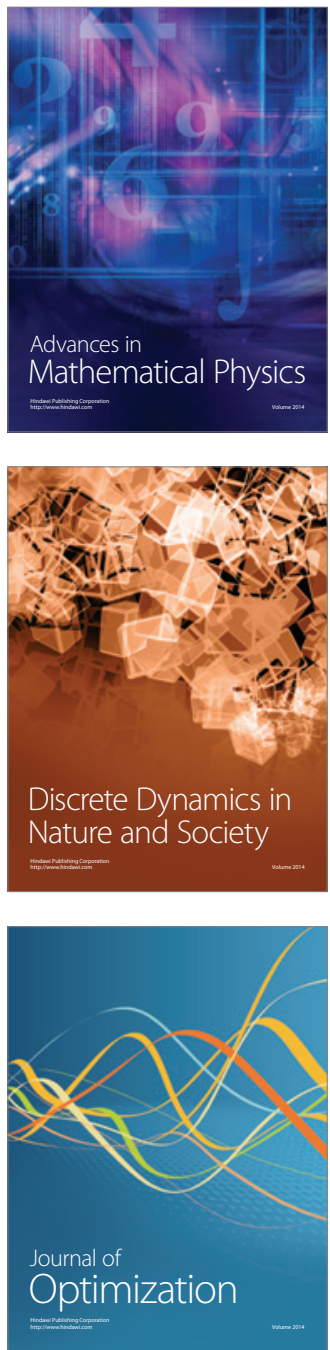